\title{
Generation of Synthetic Electrical Load Profiles for Rural Communities in Developing Countries - Applied in Fiji
}

\author{
D. Norta ${ }^{1,3}$, S. Kopietz ${ }^{12}$, S. Hien ${ }^{1}$, S. Neshvad ${ }^{3}$, Fiji-Team ${ }^{1}$ \\ ${ }^{1}$ Engineers Without Borders Luxembourg, Campus Kirchberg \\ 6, rue Richard Coudenhove-Kalergi, 1359 Luxembourg (Luxembourg) \\ Phone number: +352 466644 5762, e-mail: norta@ewb-luxembourg.org, hien@ewb-luxembourg.org, \\ fiji@ewb-luxembourg.org \\ ${ }^{2}$ Hochschule Trier, Schneidershof, 54293 Trier, Germany, e-mail: kopietzs@hochschule-trier.de \\ ${ }^{3}$ Reliable Decentral Energy Systems \\ SnT, SystemsUniveristé \\ Campus Kirchberg - 6, rue Richard Coudenhove-Kalergi, 1359 Luxembourg (Luxembourg) \\ Phone number:+352 466644 5762, e-mail: david.norta@uni.lu, surena.neshvad@uni.lu
}

\begin{abstract}
The electricity supply of developing countries undergoes massive changes. Due to the high dependency on fossil fuel imports, a lot of developing nations support the implementation of renewable generation schemes. To install an economical generation setup the generation capacity, as well as the consumption has to be balanced. Due to the often weak electricity infrastructure like the non-availability of a grid connection the systems have to operate most likely in the standalone mode. Therefore, it is important to predict the consumption patterns of the supplied society. A program to create easily synthesized load profiles for a target community, by collecting simple information about the connected consumers and operation times, is proposed to help within the design process of a power system.
\end{abstract}

\section{Key words}

Synthetic Load Profile, Renewable Energies, Stand-Alone System, Developing Country, Distributed Generation, Hydropower

\section{Introduction}

In the last decade the share of renewable energies within the global generation portfolio increased from 2004 to 2014 from 85 to $657 \mathrm{GW}$ of installed capacity excluding hydropower [1]. On the one hand industrialized countries replace their fossil generation capacities slowly by renewable generators, on the other hand, developing nations replace and open up new supplied regions with the renewable resources. In the latter case stand-alone systems are used if a grid connection is not available or too costly to be installed [2].
The so called base of the pyramid societies, living in the target region for the application of the proposed program, have not been studied by larger businesses intensively due to lacking prosperity [3]. Therefore, also the power consumption behaviour is not properly analysed.

\section{Motivation}

The program was developed within an Engineers Without Borders Luxembourg project in Fiji, for the Queleni village on the eastern Taveuni island. Motivated by the idea to create a universal and simple tool to predict the villages power demand, for the dimensioning of a small stand-alone hydropower scheme to supply the village with renewable electricity.

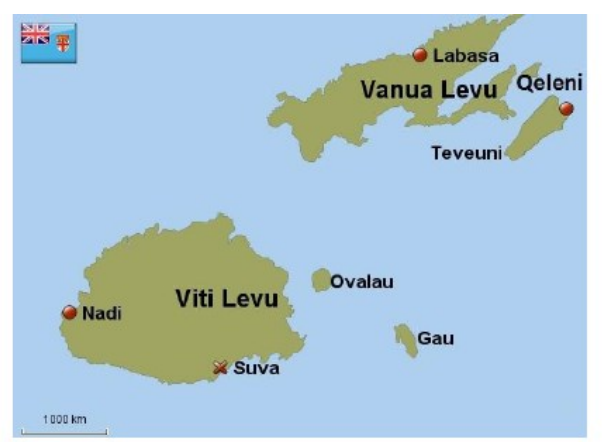

Figure 1 Map of Fiji islands, with the target village Queleni on Taveuni (indicated by a red dot), on the right side of the map.

Fiji is located in the South Pacific and consists of about 300 islands of which about 100 are populated. Several 
main islands have more developed electricity grids, but the majority of the islands have no organized electricity supply. Therefore, the villagers develop their own solutions, mainly based on diesel generators or small solar systems.

Small hydropower systems in the micro power range $(<100 \mathrm{~kW})$ do not play a role in the country so far. A rural renewable electrifcation scheme emphasized by the Fijian government promotes hydropower projects on the country side [4].

Due to the high initial investment cost of hydropower schemes compared to solar photovoltaic and windpower systems a proper dimensioning on the power demand is needed, especially for stand-alone systems, since all excess power is often dumped by heating up a water flow, to balance demand and generation. Generally, the collection of reliable energy cost information for rural non-electrified settlements prevents the market entry and the interest of larger energy supplier. Therefore, the publication should provide a program helping the target community and interested entities to develop either alone or together a viable energy supply concept for the settlements [5].

\section{Methodology}

The idea proposed in this publication is to provide synthesized load profiles for a rural settlement in a developing country using the proposed program. The following steps have to be followed.

1. Collection of number of consumer for every house,

2. collection of information concerning the operation hours of the consumers for every house,

3. feeding the program with the collected data,

4. Analysing the load curve.

The program is designed with a clear interface and can be also operated by non-technicians. The following table gives a rough understanding about the plethora of consumers found in the analysed village of Queleni, see table one. Based on a report of the department of energy of the Fijian government including the analysis of 11 villages on Taveuni, it can be seen that there are about 50 houses in each village with about 5.5 inhabitants per house. The demand is per house is in average $0.39 \mathrm{~kW}[6]$.
Table 1 Average power consumption of different devices used in the rural Fijian settlement $[7,8]$.

\begin{tabular}{|l|c|}
\hline Consumer & Power [Watt] \\
\hline Light & 9 \\
\hline Mobile Phone & 10 \\
\hline Radio & 40 \\
\hline Fan & 40 \\
\hline TV & 65 \\
\hline DVD-Player & 20 \\
\hline Fridge & 185 \\
\hline Laundry Machine & 300 \\
\hline Computer & 250 \\
\hline
\end{tabular}

In the second step the information of the operation time and operation period of the day is collected, the behaviour of several households in Queleni can be seen in the following table.

Table 2 Operation period and time of different electrical devices in rural Fijian households [7,8].

\begin{tabular}{|l|c|c|c|l|}
\hline Consumer & $\begin{array}{l}\text { Power } \\
{[\mathrm{W}]}\end{array}$ & $\begin{array}{l}\text { Operation } \\
\text { time }[\mathrm{h}]\end{array}$ & $\begin{array}{c}\text { Quantity } \\
\text { range }\end{array}$ & Operation period \\
\hline Light & 9 & $1-6$ & $2-5$ & $18: 00-24: 00$ \\
\hline $\begin{array}{l}\text { Mobile } \\
\text { Phone }\end{array}$ & 10 & 3 & 1 & $06: 00-24: 00$ \\
\hline Radio & 40 & $1-14$ & 1 & $10: 00-24: 00$ \\
\hline Fan & 40 & $1-6$ & 1 & $10: 00-22: 00$ \\
\hline TV & 65 & 3 & 1 & $18: 00-24: 00$ \\
\hline $\begin{array}{l}\text { DVD- } \\
\text { Player }\end{array}$ & 20 & 3 & 1 & $18: 00-24: 00$ \\
\hline Fridge & 185 & 4 & 1 & $00: 00-24: 00$ \\
\hline $\begin{array}{l}\text { Laundry } \\
\text { Machine }\end{array}$ & 400 & $2-3$ & 1 & $07: 00-24: 00$ \\
\hline Computer & 250 & $2-6$ & 1 & $08: 00-14: 00$ \\
\hline Speaker & 300 & $2-3$ & 1 & $07: 00-17: 00$ \\
\hline Printer & 200 & $1 / 4$ & 1 & $07: 00-14: 00$ \\
\hline
\end{tabular}

\section{A. Village Structure on Taveuni Island}

A remote rural Fijian village consists of different kinds of buildings, which can rouglhly be split in private homes and public buildings. Workshops and small industrial sites are normally not found on the countryside, those places are mainly located close to larger settlements with a central power supply.

Private homes have, depending of the owners income different levels of electric consumption. Therefore, the program provides space for the definition of three different houses to specify their inhabitants different level of power consumption. The village of Queleni took was electrified two decades ago by a governmental program, so that every house has several tube lights and electrical sockets and is connected to the central Diesel power generator by earth cables. Depending on the inhabitants ability and willingsness of maintenance of the electric 
infratrsucture within their houses the mentioned three consumer types can be distinguised.

The simplest electrified homes are equiped with only some tube lights or light bulbs (less than five). Furthermore, elctric sockets are provided which are rarely used, due to the high investment cost of electrical consumer on the countryside. Nevertheless it was seen that nearly every house has at least one mobilephone which has to be charged within a steady rhythm.

The second type of house has several lights as the simple kind, a radio or stereo system and a TV including a DVD player due to the limited access to sattelite TV.

The largest consumer are the houses of the wealthier inhabitants using lights, a radio, TV, mobile fans, fridges (mainly deep freezer) laundry machines and also computer (mainly laptops).

Additionally to the private homes it is important to introduce the consumer within the public buildings, the churches, village hall and school.

On Taveuni islands there are mainly Christians living within the villages. Indo-Fijians with their respective relegions are mainly living close to the larger cities on the two main islands, the remote islands where mainly not inhabited by the Indian settlers, invited to live in the British colony after 1879 [9].

The Christians within the villages are following five main directions, which leads often to several churches within each village [10]. But the installed consumer are comparable to the one's within the village hall, namely lights and fans, but sometimes also speaker for the priest. The main consumption takes place during the morning and evening service, on Sundays also around noon. The observed times are in the morning (6:00-10:00) and in the evening (18:00-22:00).

The village hall is mainly used during the evenings for village functions and the social get together. During daytime, most of the villagers work for their daily living on the local plantations or go for fishing. Therefore, the main consumer are lights and depending on the local power supply ceiling fans, so it will can be treated as a church within the program.

The school is normally used by children from several villages. The Queleni school has the following consumer, lights, fans, phone charger, printer and several laptops and a TV. The working hours are mainly during the day so that the contribution during the night is limited.

\section{Results and Analysis}

\section{B. Starting the Program}

In the next step the program is fed with the collected information by typing the information in the interface, seen in figure two. Three different types of houses can be distinguished and the number of houses of the same kind per village is used to multiply their demand. Also the energy demand of public buildings like a churches/village hall and school can be specified in the program.

It is important to note that the entered number of consumer seen in figure two with the rated power mentioned in table one can also be 0 , in case a specific consumer is not available.

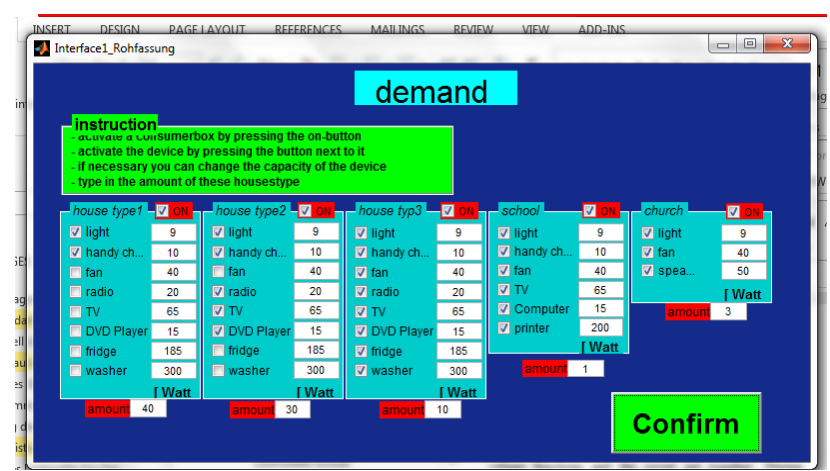

Figure 2 Program Interface.

Once the information is entered in the interface and it is confirmed by clicking on the ,confirm“ button a synthetic loadprofile is calculated, using the energy demand information of the 5 different buidling types.

\section{C. . Exemplary Results}

For the exemplary simulation 80 households are considered in total, as well as one school and and three churches and a village hall. The houses are of the following kind; 10 times house of type one, 30 times house of type two and 40 times house of type 3 .

Hereby the different consumer of the buildings are specified as followed:

- Private households

○ 40 time kind 1: 1-5 lights 9W, 1 phone charger $10 \mathrm{~W}$

- 30 times kind 2: 1-5 lights 9W, 1 phone charger $10 \mathrm{~W}, 1$ radio $20 \mathrm{~W}, 1 \mathrm{TV} 65 \mathrm{~W}$, 1 DVD Player $15 \mathrm{~W}$

- 10 times kind 3: 1-5 lights $9 \mathrm{~W}, 1$ phone charger $10 \mathrm{~W}, 1$ fan $40 \mathrm{~W}, 1$ radio $20 \mathrm{~W}$, 1 TV 65W, 1 DVD Player 15W, 1 fridge $185 \mathrm{~W}, 1$ laundry machine $300 \mathrm{~W}$

- Church/village hall (3 churches +1 village hall with the same specification), operation time 610AM and 8-10PM: 6 lights 9W, 4 fans 40W, 6 speaker $50 \mathrm{~W}$

- School (236 students 9 classrooms), operation time 8AM-2PM: 8-36 lights 9W, 1-9 fans 40W, 1 TV $65 \mathrm{~W}, 1$ laptop $15 \mathrm{~W}, 1$ printer $200 \mathrm{~W}$, 1phone charger $10 \mathrm{~W}$

This yields to a maximum power for a simulated period of 10 years with a 15 min time resolution of about $10.5 \mathrm{~kW}$ at 9PM. It can be clearly seen that there is a evening peak of the comsumption. Therefore, the propsosed choice of hydropower seems to be favorable compared to a solar PV 
solution, due to the limited solar radiation and so generation in the evening.

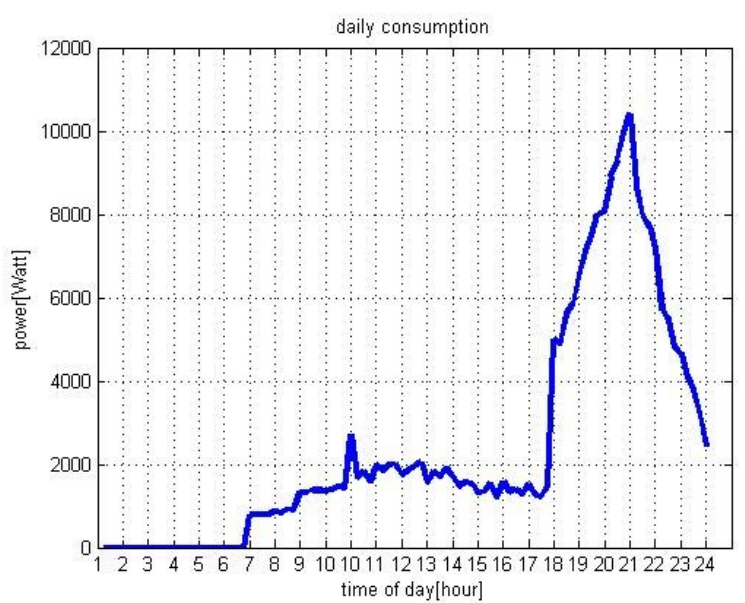

Figure 3 Exemplary synthetic Loadcurve of the Queleni village for one day with the consumer specified above.

Within the time "operation period" a random function switches consumer on and off until the specific daily operation time is reached. This function is included to adapt the prediction to the consumer behaviour.

Finally, a load curve is plotted and can be studied by the system designer, see figure three. Using the proposed program a synthetic load curve can be designed easily by studying a maxmimum of 5 different buildings and their consumer. The information about the consumer and their quantity can be easily collected in a village meeting, as done in Fiji. The load curve is an important information for the design process of a suitable power supply of a settlement, as well as for the further understanding of the base of the pyramid market participants' electricity consumption behaviour.

\section{Conclusion}

To predict the power consumption of not yet electrified settlements is an important step on the way to their electrification. Due to the limted information available describing the consumption behaviour or remote societies it is important to have flexible program which helps calculating the needed information for the dimensionsing and choice of the right generator. Using the remote rural Fijian village Queleni as a lighthouse settlement for the proposed idea, such a flexible program was written to help the prediction of individual load profiles for the mentioned village. The program is written in a comprehensive way and uses time thresholds for the power consumption of different available devices to take into account the individual behaviour of the inhabitants. Three different kinds of houses and their electric consumer, as well as schools and churches/village hall can be defined within the program. Finally, a load profile is generated as a result of a simulation for 3650 load profiles for a period of ten years, to include in a sufficient way the influence of the random behaviour of the inhabitants power consumption within their consumption time thresholds.

\section{References}

[1] REN21, "RENEWABLES 2015 GLOBAL STATUS REPORT Key Findings 2015", Paris, France, 2015

[2] Govinda R., Timilsina, Lado Kurdgelashvili and Patrick A. Narbel, "A Review of Solar Energy Markets, Economics and Policies" The World Bank, Washington D.C., USA, 2011

[3] London, T., Hart, S. L. "Reinventing strategies for emerging markets: beyond the transnational model", Journal of International Business Studies, 35(5), p. 350-370., 2004

[4] IRENA "FIJI RENEWABLES READINESS ASSESSMENT",Abu Dhabi, 2015

[5] Van Acker, V., Szablya, S.J., Louie, H., McLean Sloughter, J., "Survey of energy use and costs in rural kenya for community microgrid business model development", IEEE Global Humanitarian Technology Conference (GHTC), 2014

[6] Department of Energy, Government of Fiji, "Fiji's Hydro Potential Report Volume 1 1995-2006”, Suvar, Fiji, 2009

[7] Mission Report "FJI-IOG01-project", Ingenieure ohne Grenzen Deutschland, Engineers Without Borders (EWB) Germany, Berlin, 2015

[8] D. Norta, technical project manager EWB Germany and Luxembourg Fiji projects, personal communication, 2015

[9] Brij V Lal, "Girmitiyas: The origins of the Fiji Indians", Chapter 5, 1983

[10] Fiji Bureau of Statistics - Key Statistics, "POPULATION BY RELIGION AND PROVINCE OF ENUMERATION, FIJI : 2007 CENSUS ”, 2012 